\title{
Corruption, growth and ethnic fractionalization: a theoretical model*
}

\author{
Roy Cerqueti \\ Department of Economic and Financial Institutions \\ University of Macerata \\ Raffaella Coppier \\ Department of Economic and Financial Institutions \\ University of Macerata \\ Gustavo Piga ${ }^{\dagger}$ \\ Department of Economics and Territory \\ University of Rome Tor Vergata
}

\begin{abstract}
This paper analyzes the existing relationship between ethnic fractionalization, corruption and the growth rate of a country. We provide a simple theoretical model. We show that a nonlinear relationship between fractionalization and corruption exists: corruption is high in homogeneous or very fragmented countries, but low where fractionalization is intermediate. In fact, when ethnic diversity is intermediate, constituencies act as a check and balance device to limit ethnically-based corruption. Consequently, the relationship between fractionalization and growth rate is also non-linear: growth is high in the middle range of ethnic diversity, low in homogeneous or very fragmented countries.
\end{abstract}

Keywords: corruption, ethnic fractionalization, monitoring cost, economic growth.

JEL Codes: D73, K42, O43.

\footnotetext{
*The authors would like to thank Elisabetta Iossa, Arsen Palestini, the seminar participants at the 24th Annual Congress of the European Economic Association, August 23-27, 2009 and at the 15th World Congress of the International Economic Association, June 25-27, 2008, Istanbul, for their very helpful suggestions.

${ }^{\dagger}$ Corresponding author: Gustavo Piga, Department of Economics and Territory, University of Rome Tor Vergata, Via Columbia 2, 00133, Rome, Italy,

E-mail:gustavo.piga@uniroma2.it
} 


\section{Introduction}

Much research has been directed at explaining the causes and the consequences of corruption. Different levels of corruption have been attributed to differences in religious tradition, colonial experiences (see e.g. Treisman, 2000), level of development (see e.g. Blackburn et al., 2010), levels of decentralization (Treisman, 2000, Fisman and Gatti, 2002 and Lessmann and Markwardt, 2010), competition among bureaucracies (see e.g. Drugov, 2010 ) or to the availability of natural resources (see e.g. Vicente, 2010 and Bhattacharyya and Hodler, 2010). Researchers have also investigated the effects of corruption on investment and growth (see e.g Mauro, 1995), on international trade (see e.g. Lambsdorff, 1998 and Musila and Siguè, 2010), on income inequality (see e.g. Dobson and Ramlogan-Dobson, 2010), on the volatility of the economic growth rate (see Evrensel, 2010) and on misallocation of resources (see e.g. Acemoglu and Verdier, 1998 and 2000). Our paper tries to provide additional light on the causes and consequences of corruption by suggesting that a further determinant of it, ethnic diversity, can produce a novel and non-linear impact on output growth.

In recent years, the economic interest in ethnic fractionalization ${ }^{1}$ has increased, in part due to greater cross-border movements. Although ethnic diversity is an omnipresent theme throughout history, economists are only recently starting to pay attention to it. Journalists report on ethnic diversity mostly when it erupts into bloodshed, although ethnic fractionalization does not automatically, nor exclusively, imply ethnic conflict. The recent literature has claimed that cross-country differences in ethnic diversity explain a substantial part of cross-country differences in public policies, political instability and other economic factors associated with long-run growth (see Easterly and Levine 1997). Political economy models suggest that polarized societies will be both prone to competitive rent-seeking by different groups and have difficulty agreeing on public goods like infrastructure, education and good policies (Alesina and Drazen 1991; Shleifer and Vishny 1993; Alesina and Spoloare 1997). Alesina and Drazen (1991) describe how a war of attrition between interest groups can postpone macroeconomic stabilization. Alesina et al. (1999) present a

\footnotetext{
${ }^{1}$ In our paper we will consider as ethnic group one of human beings whose members identify with each other usually on the basis of common cultural, linguistic, religious, behavioral or biological traits. In this respect, we will use interchangeably term ethnic fractionalization or ethnolinguistic fractionalization since in the definition of the concept of "ethnic group" it is difficult to distinguish between ethnic and linguistic variables. In fact, language is a fundamental part of the criterion used by ethnologists and anthropologists to define the concept of ethnicity. Indeed, Alesina et al. (2003) compute a measure of ethnic fractionalization, "ethnicity", the definition of which involves a combination of racial and linguistic characteristics. Also, Atlas Norodov Mira (1964), in order to compute the ELF index, mainly used language to define groups, even if it sometimes refers to notions of race or national origin in order to distinguish between different groups.
} 
model linking heterogeneity of preferences across ethnic groups in a city to the amount and type of public goods the city supplies. Results show that the shares of spending on productive public goods are inversely related to the city ethnic fragmentation. Mauro (1995), La Porta et al. (1999) and Alesina et al. $(2003)^{2}$, amongst others, show that ethnic fractionalization is negatively correlated with measures of infrastructure quality, literacy and school attainment.

Ethnolinguistic fractionalization appears to be responsible for a variety of corruption-related phenomena (Shleifer and Vishny 1993; Svensson 2000). Svensson (2000) and Mauro (1995) find that corruption is higher the higher ethnic diversity. Svensson (2000) also finds that corruption increases where there is more foreign aid in an ethnically-divided society although this is not the case in an ethnically-homogeneous one. In Shleifer and Vishny (1993) corruption may be particularly damaging when there is more than one bribetaker. If each independent bribe-taker does not internalize the effects of her/his bribes on the other bribe-takers' revenues, then the result is more bribes per unit of output and less output. Ethnically-diverse societies may be more likely to yield independent bribe-takers, since each ethnic group is responsible for a region or ministry in the power structure. For this reason Mauro (1995) regresses growth on corruption assuming an index of ethnolinguistic fractionalization as an instrumental variable to test the hypothesis that more fractionalization (and therefore more corruption) is associated with lower economic growth ${ }^{3}$.

The literature has thus stressed the negative role of ethnic fragmentation on corruption and therefore on economic growth. But alongside this negative role, there is the possibility of a positive role for ethnic diversity. In fact as Alesina and La Ferrara (2005) say:

"Is ethnic diversity "good" or "bad" from an economic point of view, and why? Its potential costs are fairly evident. Conflict of preferences, racism, prejudices often lead to policies which are suboptimal from the point of view of society as a whole, and to the oppression of minorities which can explode in war or least in disruptive political instability. But an ethnic mix also brings about variety in abilities, experiences, cultures which may be productive and may lead to innovation and creativity. The United States are the quintessential example of these two faces of racial relations in a "melting pot"."

Analogously to Tångeras and Lagerlöf (2009), the role of the degree of

\footnotetext{
${ }^{2}$ These results are very strong in regressions without income per capita (which may be endogenous to ethnic fractionalization). They lose some of their significance when on the right-hand side one controls for GDP per capita.

3 "Sociological factors may contribute to rent-seeking behavior. An index of ethnolinguistic fractionalization (societal divisions along ethnic and linguistic lines) has been found to be correlated with corruption. Also, public officials are more likely to do favors for their relatives in societies where family ties are strong". Mauro (1997)
} 
ethnic diversity of a country (i.e. the number of ethnic groups) has been explored to describe and explain an economic phenomenon. While Tångeras and Lagerlöf's analysis is related to the probability of the occurrence of a civil war, we discuss the level of corruption of a country and its relationship to ethnic fragmentation. In particular, we contribute to this debate by analyzing how ethnolinguistic fractionalization can influence the extent of corruption.

We propose a descriptive model since, as Collier (2001) and Alesina et al. (2003) emphasize, it is hard to see any policy implications arising from fractionalization, because there is little that a country can legitimately do about its ethnic composition without affecting other non-economic variables which are not the object of this study.

Indeed, our descriptive paper does not aim at suggesting optimal ethnic policies directed at reducing corruption or at allowing growth to increase. One might note however that, for a given ethnolinguistic fractionalization, a policy aspiring to achieve a fair and balanced representation of ethnic groups within the administrative public sector machine (even in the presence of constituencies with a majority of votes) could help not only in reinforcing mutual understanding and muting fake stereotypes but also in making the fight against corruption more credible. Minority rights in this respect could prove helpful.

In our model, we rely on a society populated by bureaucrats, controllers and entrepreneurs, producing a single good. The population is fractionalized in $n$ different ethnic groups. A theoretical game is constructed as follows: the entrepreneur has to choose between the traditional technology and the modern technology. We assume that the modern technology has higher productivity than the traditional technology. In order to access to the modern technology, the entrepreneur has to request a concession from the bureaucrat. Since the concession has an expiration date, the entrepreneur needs to submit the project to the Public Administration in each period, and each concession submission is independent from the previous ones. To capture these characteristics of the problem, we develop a one-shot game. We also assume that the entrepreneur must acquire a bureaucrats approval for the project (see Yoo, 2008). The bureaucrat can ask the entrepreneur for a bribe in exchange for providing the concession. The entrepreneur can agree or refuse to pay the bribe. Moreover, we consider the presence of monitoring activity. Monitoring activity is related to the intervention of the controllers in order to penalize illegal interactions between entrepreneurs and bureaucrats.

In our work, the optimal monitoring level is endogeneously derived. We assume that ethnic fractionalization has two opposite effects: on the one hand, it increases the cost of monitoring but, on the other hand, high ethnic fractionalization generates an increase in the probability of being reported, because the controller reports the corrupt transaction only if the bureaucrat 
belongs to a different ethnic group from that of the controller. Indeed, for certain levels of ethnic diversity, fragmentation takes on a positive role in controlling corruption because it increases the level of control between different ethnic groups.

The findings of the present paper are comparable to the ones in Tångeras and Lagerlöf (2009): indeed, in both cases, the influence of the degree of ethnic diversity seems to be more powerful when the country is neither homogeneous nor highly fragmented. The common root of these results can be found in the presence of two competitive effects due to the number of ethnic groups. In particular, in our paper, the effect of monitoring corruption is low either in homogeneous or very fragmented countries, while it is high when the level of ethnic diversity is intermediate.

In this context, we also find a non-linear relationship between ethnic diversity, corruption and growth: in fact, homogeneous and fragmented societies are characterized by high corruption and low economic growth. In the middle range of ethnic diversity, the ethnic factor acts as a "control" on corruption thus producing greater economic growth.

In Figures 1a, 1b, 1c, we scatter the growth rate in 2007 against the measure of ethnic fractionalization proposed in Alesina et al. (2003) for World Countries, Democratic Countries and OECD Countries, respectively ${ }^{4}$. As the Figures indicate, intermediately fractionalized countries have the highest growth rate. The Figures also show the implementation of a formal regression between the ethnic fractionalization index and the growth rate via quadratic polynomial function. There is evidence that a reversed U-shaped function seems to fit the scatter plot well ${ }^{5}$.

The rest of the paper is organized as follows. In section 2, we present the model and the related theoretical game. In section 3, the relationship between the monitoring level, corruption and economic growth is studied. In section 4, using the results of the previous sections, we endogeneize the monitoring level of controllers and prove that a non-linear relationship between fractionalization -via corruption- and growth exists. Section 5 concludes.

\footnotetext{
${ }^{4}$ See Appendix A for the list of the countries.

${ }^{5}$ The R-squared are 0.03327, 0.07805 and 0.1309 for World, Democratic and OECD Countries, respectively. The second-order best fit polynomial is $P(x)=-14.86 x^{2}+$ $11.96 x+2.627, P(x)=-21.3 x^{2}+16.81 x+1.675$ and $P(x)=-0.102 x^{2}+0.9078 x+2.511$ for World, Democratic and OECD Countries, respectively. We point out that the analysis developed in our model does not aim at providing forecasts, but only at stating the relationship between variables. In particular, the relationship between growth rate and fractionalization is under scrutiny in our paper. In this situation, standard statistics arguments guarantee that the fit parameters such as R-squared are less relevant, because no one would expect fractionalization to explain a high percentage of the growth rate, as the growth rate of a country is affected by many other factors. The best fit parameters, as expected, improve when restricting from World Countries to Democratic Countries, and then to OECD Countries.
} 

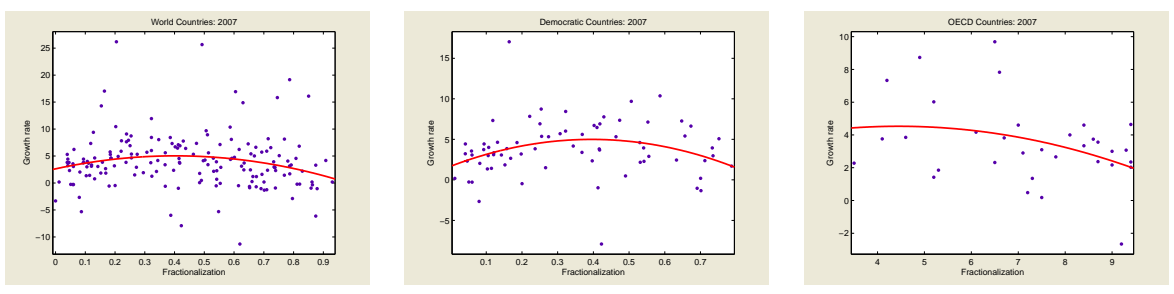

Figure 1: The scatter plot is the growth rate versus the ethnic coefficient. The line is the best fit quadratic function.

\section{The theoretical game model}

Let us consider an economy producing a single homogeneous good and composed of a continuum of 3 types of agents: bureaucrats, controllers and entrepreneurs. The controllers monitor bureaucrats' behavior in order to weed out or reduce corruption. Firms manufacture a homogeneous product $y$ using either one of two technologies ${ }^{6}$ with constant return to scale: the modern technology and the traditional technology. Each entrepreneur is assumed to have the same quantity of capital $k$. The product may either be manufactured for consumption purposes or for investment purposes.

The modern technology output is:

$$
y=a_{M} k
$$

Here we deal with the grant of a concession ${ }^{7}$ to the entrepreneurs. In order to obtain their concession, the entrepreneurs need to submit a project to the Public Administration.

The entrepreneur may access the traditional technology without any concession being issued by the Public Administration. In this case the output is:

$$
y=a_{T} k
$$

From here on, it will be assumed that $a_{M}>a_{T}$ and therefore that the modern technology is more profitable than the traditional technology.

\footnotetext{
${ }^{6} \mathrm{As}$ in $\mathrm{Li}$ et al. (2000) an agent can produce in either the traditional or the modern technology. Productivity of the modern technology is greater than that of the traditional technology. The advantage of the traditional technology is that it is not subject to expropriation, while that of the modern technology is. The rationale is that entrepreneurs with the modern technology must obtain permits and concessions and are vulnerable to the effects of corruption. This hypothesis could be interpreted by regarding the modern technology as an innovative technology (e.g. telecommunications) which is still in need of State regulation.

${ }^{7}$ The concession, once granted, has an expiration date and must be renewed at the end of its lifetime. As we will see, we construct and develop a one-shot game, and so the one-period concession seems to be suitable for modelling purposes. After the expiration date, the game is repeated in an identical manner.
} 
The bureaucrat receives a salary $w^{8}$. In this model, the bureaucrat may decide to issue a concession only in exchange for a bribe. Since the gross profit resulting from the investment in the modern technology is higher than the one in the traditional technology, the entrepreneur may find it worthwhile to negotiate and accept the bribe requested by the corrupt bureaucrat in order to obtain the necessary concession to access the modern technology. The bureaucrat may decide not to ask for a bribe and to issue the concession to all those who submit a project, or $\mathrm{s} /$ he may decide to ask for a bribe in exchange for such a concession. The State monitors bureaucrats -via controllers- in such a way that $q_{i}$ is the probability that the bureaucrat belonging to the $i$-th ethnic group is reported ${ }^{9}$. In our model, we assume that the bureaucrat detected in a corrupt transaction will be punished with a fine $m k^{10}$. In contrast, the loss of reputation incurred by the entrepreneur detected in a corrupt transaction may affect her/his business. More precisely, it is common knowledge ${ }^{11}$ that the $j$-th entrepreneur incurs a specific value $c_{j} k$ to the loss of reputation derived from being caught in a corrupt transaction $^{12}$ where $c_{j} \in[0,1]$.

The controller must monitor the bureaucrat's behavior and s/he puts a level of monitoring $p$ in place. Since the pioneer work of Allport (1954) on the theory of prejudice and following the Social Identity Theory (Tajfel and Turner, 1986), early work established that patterns of intergroup behavior can be understood considering that individuals may attribute positive utility to the well-being of members of their own group and negative utility to that of members of others group (see e.g. Tajfel et al. 1971). The simple fact of belonging to a group can lay foundations of prejudice, judgmental biases and

\footnotetext{
${ }^{8} \mathrm{It}$ is assumed that no arbitrage is possible between the public and the private sector and that therefore there is no possibility of the bureaucrats becoming entrepreneurs, even if their salary $w$ were lower than the entrepreneur's net return. This happens because the bureaucrat individuals in the population have no access to the capital markets, but only a job, and therefore may not become entrepreneurs.

${ }^{9}$ In our model, there is an implicit public budget constraint so that the State uses revenues which derive from a lump sum taxation and fines imposed on bureaucrats caught in corrupt transaction, to pay the wages and to put in place redistributive policies. However, there is no space for financing public productive expenditure. Since this is not the focus of our work, we do not make that public constraint explicit.

${ }^{10}$ The punishment for the detected bureaucrat is not a constant, but following RoseAckerman (1999), it is a function of the bureaucrat's payoff. In fact, in the suggested model, since the obtained bribe is a function of $k$, the punishment is assumed to be a function of $k$.

${ }^{11}$ The entrepreneurs experience different reputation costs when they are detected in corrupt transactions. The differences derive from the economic relevance of entrepreneurial activity. Hence, it is possible to attach a specific value to the entrepreneurs' reputation costs, and such values belong to the bureaucrats' information set.

${ }^{12}$ Based on the statements of Rose-Ackerman (1999), the punishment for the entrepreneur is not a constant, but rather a function of the entrepreneur's payoff. The punishment for the entrepreneur is considered as a function of the investment determining the size of the profits.
} 
intergroup discrimination towards outgroups ${ }^{13}$. Following this literature, we assume that only if the controller meets a corrupt bureaucrat belonging to a different ethnic group will s/he report the corruption ${ }^{14}$. We hypothesize that "The Department of Controllers" is divided in proportion to ethnic groups ${ }^{15}$. Let $\omega_{i} \in[0,1]$ the probability that an individual belongs to the $i$-th ethnic group, with $i=1, \ldots n .{ }^{16}$ Following Alesina and La Ferrara (2005), we rely on a country where the different ethnic groups are of the same size. Therefore

$$
\omega_{i}=\omega=\frac{1}{n} .
$$

The controller earns $\alpha p$ from the State for the monitoring level $p$ and $\mathrm{s} /$ he encounters increasing difficulty in monitoring entrepreneurs as the number of ethnic groups grows. The optimal monitoring level $p$ will be derived endogenously in the model and it will be a non linear function of ethnolinguistic fractionalization $n$. In the rest of the paper, we refer to the entrepreneur payoff by a superscript $(E)$ and to the bureaucrat payoff by a superscript $(B)$.

Our model can be formalized by introducing the following three-period dynamic game:

(1) At stage one of the game, the entrepreneur should decide in which technology to invest, i.e. whether to invest her/his capital in the modern or in the traditional technology. Such a decision is tantamount to the decision of whether or not to submit the project to the Public Administration, considering that a concession is needed to invest in the modern technology. Project submission does not result in the automatic issue of the concession by the bureaucrat, in that the bureaucrat may refuse to grant the concession unless a bribe $b^{d}$ is paid.

\footnotetext{
${ }^{13}$ This prejudice is reinforced by the nationalist attitude of a population. Corneo (2010) stresses in his theoretical and empirical analysis that ability is an explanatory factor of nationalism: in fact, parents of low-ability children instill nationalism in their offspring which will have, therefore, more hostile relations with immigrants.

${ }^{14}$ It is worth noticing that the controllers do not have information about the bureaucrat's ethnic group before the check. In fact, we do not deal with political corruption but bureaucratic corruption (petty corruption). In this case, the controller does not know which entrepreneurs to control until a superior tells her/him the assigned tasks and s/he cannot refuse to control the entrepreneurs which have been allocated.

${ }^{15}$ Notice that our model does not apply if ethnic fractionalization is not reflected also in institutions, as it is often the case in dictatorships.

${ }^{16}$ This assumption we make allows us to derive closed form formulas for the analysis of the growth rate and the reputation of the entrepreneurs with respect to fractionalization and the probability of being detected. We can only say that whenever the ethnic group $i$ is dominant then, ceteris paribus, the probability $q_{i}$ to be detected is lower and corruption is greater. In the case of non homogeneous ethnic groups, our model should be interpreted as a normative model highlighting the impact of electoral and administrative systems where ethnic representation in government and/or civil servants is proportional to the demographic base.
} 
(1.1) If the entrepreneur decides not to submit the project (investing in the traditional technology) the game ends and then the payoff vector for bureaucrat and entrepreneur is:

$$
\underline{\pi}_{1}=\left(\pi_{1}^{(B)}, \pi_{1}^{(E)}\right)=\left(w, a_{T} k\right) .
$$

(1.2) If the entrepreneur decides to submit the project, $\mathrm{s} /$ he asks the bureaucrat to issue the concession. In this case, the game continues to stage two.

(2) At stage two, the bureaucrat decides the amount to ask for as a bribe $b^{d}$ for issuing the concession.

(2.1) If the bureaucrat, facing an entrepreneur who has submitted a project, decides not to ask for a bribe $\left(b^{d}=0\right)$ for issuing the concession, then the game ends and the payoff vector for bureaucrat and entrepreneur is:

$$
\underline{\pi}_{2}=\left(\pi_{2}^{(B)}, \pi_{2}^{(E)}\right)=\left(w, a_{M} k\right) .
$$

(2.2) If the bureaucrat decides to negotiate the payment of a bribe $\left(b^{d}>0\right)$ with the entrepreneur in order to obtain the concession, the game continues to stage three.

(3) At stage three, the payoffs will depend on whether, on one hand, the agreement between the bureaucrat and the entrepreneur is achieved or not and, on the other hand, on whether the bureaucrat and the entrepreneur are reported (with probability $q_{i}$ ) or not.

(3.1) If agreement is not reached, the payoffs will depend on whether the bureaucrat is reported (with probability $q_{i}$ ) or not. If the bureaucrat is detected, then she/he is punished, therefore $\mathrm{s} / \mathrm{he}$ receives her/his salary minus a fine $m k$. The entrepreneur obtains the concession and can thus invest in the modern technology. Otherwise, the bureaucrat receives her/his wage and refuses to grant the concession to the entrepreneur who must invest in the traditional technology. Therefore, the game ends with a payoff vector which is random, in that it depends on the probability of being reported:

$$
\begin{cases}\left(w-m k, a_{M} k\right), & \text { with probability } q_{i} \\ \left(w, a_{T} k\right), & \text { with probability } 1-q_{i} .\end{cases}
$$

The expected payoff vector is:

$$
\underline{\pi}_{3}=\left(\pi_{4}^{(B)}, \pi_{4}^{(E)}\right)=\left(w-q_{i} m k, q_{i} a_{M} k+\left(1-q_{i}\right) a_{T} k\right) .
$$

Then the game ends. 
(3.2) If agreement is not reached, the payoffs will depend on whether the bureaucrat and the entrepreneur are reported (with probability $q_{i}$ ) or not. If they are detected, then the bureaucrat receives her/his salary minus the fine $m k$ and the entrepreneur pays the reputation $\operatorname{cost} c_{j}$, but she/he is refunded the cost of the bribe paid to the bureaucrat. Otherwise, the bureaucrat receives her/his wage plus the bribe, which the entrepreneur must pay. Therefore, the game ends with a payoff vector which is random, in that it depends on the probability of being reported:

$$
\begin{cases}\left(w-m k, a_{M} k-c_{j} k\right), & \text { with probability } q_{i} ; \\ \left(w+b^{N B}, a_{M} k-b^{N B}\right), & \text { with probability } 1-q_{i} .\end{cases}
$$

The expected payoff vector is:

$$
\underline{\pi}_{4}=\left(\pi_{4}^{(B)}, \pi_{4}^{(E)}\right)=\left(w+\left(1-q_{i}\right) b^{N B}-m k q_{i}, a_{M} k-\left(1-q_{i}\right) b^{N B}-q_{i} c_{j} k\right) .
$$

When a controller monitors a corrupt transaction, s/he decides to bring a charge only if the bureaucrat belongs to a different ethnic group from that of the controller. The probability of a controller, belonging to the $i$-th ethnic group, meeting a bureaucrat belonging to the $i$-th ethnic group as well, will be equal to $\frac{1}{n}$. Then $q_{i}$ is the probability of the bureaucrat belonging to the $i$-th ethnic group being reported and it derives from the probability $p$ of being monitored and from the probability of the controller belonging to an ethnic group different from $i$. Then

$$
q_{i}=q=p\left(1-\frac{1}{n}\right), \quad \forall i=1, \ldots, n .
$$

The optimum level of $p$ derives from maximization by the controller of her/his own expected payoff (see section 4).

\section{The solution of the game}

The game may be solved by backward induction, starting from the last stage. The bribe resulting as the Nash solution to a bargaining game in the last subgame needs to be determined. Such a bribe is the outcome of a negotiation between the bureaucrat and the entrepreneur, who will be assumed to share a given surplus on an equal basis. We first determine the equilibrium bribe (see Appendix B for the proof).

Proposition 3.1. Let $q \neq 1 .{ }^{17}$ Then there exists a unique non-negative bribe $b_{j}^{N B}$, as the Nash solution to a bargaining game, given by:

$$
b_{j}^{N B}=\left[\frac{\left(a_{M}-a_{T}\right) k}{2}-\frac{q c_{j} k}{2(1-q)}\right] .
$$

\footnotetext{
${ }^{17}$ If $q=1$ this stage of the game is never reached.
} 
Proposition 3.1 shows that, when the equilibrium is reached, the entrepreneur gives half of the surplus to the bureaucrat, such a surplus being the difference in the expected return on the investment in the two different technologies (modern and traditional), net of the entrepreneur's expected costs for being detected in a corrupt transaction.

Remark 3.2. We notice that a straightforward computation gives that the equilibrium bribe $b_{j}^{N B}$ is decreasing with respect to the probability of being detected in a corrupted transaction. Therefore, increasing $q$, reduces the potential surplus that the bureaucrat and entrepreneur can share, thus reducing the bribe.

\subsection{The static equilibrium}

The game has been solved in Appendix $\mathrm{C}$ by using the backward induction method starting from its last stage. The solution of the game is formalized by the following proposition.

Proposition 3.3. Let $0 \leq \frac{\left(a_{M}-a_{T}\right)(1-q)}{q}-2 m=c^{\circ} \leq 1^{18}$.

(a) If $c_{j} \in\left[0, c^{\circ}\right)$ then the equilibrium expected payoff vector is:

$$
\underline{\pi}_{4}=\left(w-m k q+\frac{\left(a_{M}-a_{T}\right)(1-q) k}{2}-\frac{c_{j} k q}{2}, a_{M} k-\frac{\left(a_{M}-a_{T}\right)(1-q) k}{2}-\frac{c_{j} k q}{2}\right) .
$$

This is the expected payoff vector connected to equilibrium $C$ (see below);

(b) if $c_{j} \in\left[c^{\circ}, 1\right]$ then the equilibrium expected payoff vector is:

$$
\underline{\pi}_{2}=\left(w, a_{M} k\right) \text {. }
$$

This is the expected payoff vector connected to equilibrium $\mathrm{NC}$ (see below).

The previous proposition shows that we obtain two perfect Nash equilibria in the sub-games, depending on the parameter values:

- Equilibrium $\mathbf{C}$ : if $c_{j}<c^{\circ}$, the difference in gross profits between the modern sector and the traditional technology is such as to make up for the expected cost of corruption. Thus, the surplus to be shared between the entrepreneur and the bureaucrat will keep a negotiation going, the outcome of which is the bribe corresponding to the Nash solution to a bargaining game;

\footnotetext{
${ }^{18}$ Actually, this requirement allows us to avoid the trivial cases of corner solutions: when $c^{\circ}<0$, then the entrepreneurs are honest, while $c^{\circ}>1$ implies that the entrepreneurs are corrupt.
} 
- Equilibrium NC: if $c_{j} \geq c^{\circ}$, i.e. the "reputation cost" is so high that the entrepreneur would turn down a request for a bribe. Realizing this fact, the bureaucrat will refrain from asking for a bribe for issuing the concession. Thus the entrepreneur will choose the modern technology and will not be asked for a bribe by the bureaucrat.

Substantially, there are two ranges of $c_{j}$ which correspond to different corruption levels: in equilibrium $\mathbf{C}$ corruption is widespread, while it is absent in equilibrium NC.

As we have stated, our model assumes that reputation costs may vary across different entrepreneurs ( $c_{j}$ for the $j$-th entrepreneur), depending on her/his own "reputation loss" when the corrupt transaction is detected. This argument applies to each ethnic group.

The distribution of individual costs is described through a probability distribution function $F\left(c_{j}\right)$, where $j$ is the specific entrepreneur. This function represents the fraction of entrepreneurs who agree to be corrupted. By definition, $F$ is a distribution function associated to a random variable whose density function $f$ has support $[0,1]$. The shape of the function $f$ gives good information about the general level of entrepreneurs' honesty. In particular, the symmetry properties of the function $f$ provide information about the distribution of the entrepreneurs between those with a high or low reputation costs, in short the honest and the corrupt. If $f$ is a centered symmetric function, then the country has an average level of corruption, and the number of corrupted entrepreneurs balances the number of honest entrepreneurs. The case of $f$ asymmetric to the left can be associated to a country where most entrepreneurs are corrupt, while $f$ is asymmetric to the right in countries where most entrepreneurs are honest. Therefore, so that our analysis is complete, we need to provide a random law for the reputation costs which may describe the generality of the cases, depending on the value of some parameters. This purpose can be achieved by incurring the cost of adopting an unusual probability law, which is commonly used in a rather mathematical context: namely the Kumaraswamy distribution. In fact, of all the distribution functions of random variables with support in $[0,1]$, the Kumaraswamy law seems to be the more appropriate choice for $F$, since it has some features that make it suitable for modeling the different reputation costs of the entrepreneurs belonging to a given country ${ }^{19}$. However, as we will see below in Remark 3.4, the results concerning the behavior of the aggregate expected growth rate with respect to the monitoring level $q$ can be obtained, regardless of the particular shape of cost distribution.

Given the heterogeneity of entrepreneurs, their behavior will be influenced

\footnotetext{
${ }^{19}$ Further details of the mathematical definition of the Kumarawamy law with some graphical examples, together with some supporting arguments on why we use this random variable for modelling the reputation costs distribution, are provided in Appendix D.
} 
by their own reputation cost $c_{j}$. In this hypothesis we have

$$
F\left(c^{\circ}\right)=1-\left(1-\left(c^{\circ}\right)^{\alpha_{1}}\right)^{\alpha_{2}}=1-\left(1-\left(\frac{\left(a_{M}-a_{T}\right)(1-q)}{q}-2 m\right)^{\alpha_{1}}\right)^{\alpha_{2}}
$$

is the fraction of entrepreneurs belonging to the $i$-th ethnic group with a reputation cost $c_{j}<c^{\circ}$, while

$$
1-F\left(c^{\circ}\right)=\left(1-\left(c^{\circ}\right)^{\alpha_{1}}\right)^{\alpha_{2}}=\left(1-\left(\frac{\left(a_{M}-a_{T}\right)(1-q)}{q}-2 m\right)^{\alpha_{1}}\right)^{\alpha_{2}}
$$

is the fraction of entrepreneurs belonging to the $i$-th ethnic group with a reputation $\operatorname{cost} c_{j} \geq c^{\circ}$.

In contrast with the static case, in a dynamic context, as we will see in the next section, corruption influences the accumulation of capital by entrepreneurs, and thus economic growth.

\subsection{Dynamic equilibrium}

The game perspective is now expanded to review the dynamic consequences of corruption on growth and, therefore, on investment, while analyzing the entrepreneur's behavior in this respect. As noted, a manufactured product may be either consumed $C$ or invested $\dot{k}$.

We consider a constant elasticity utility function:

$$
U=\frac{C^{1-\sigma}-1}{1-\sigma}
$$

Each entrepreneur maximizes utility over an infinite period of time subject to a budget constraint. This problem is formalized as:

$$
\max _{C \in[0,+\infty)} \int_{0}^{\infty} e^{-\rho t} U(C) d t
$$

subject to

$$
\dot{k}=\Pi_{E}-C,
$$

where $C$ is consumption, $e^{-\rho}$ is the uniperiodal discount factor and $\Pi_{E}$ is the return on the investment for the entrepreneur.

Since $\Pi_{E}$ is different across equilibria, the problem is solved for the two cases $^{20}$.

This model predicts that the $j$-th entrepreneur belonging to the $i$-th ethnic group will have only one optimum equilibrium -and only one corresponding expected growth rate- depending on her/his own reputation cost.

\footnotetext{
${ }^{20}$ In the interest of clarity, we report the computation of the expected growth rate in Appendix E.
} 
- The entrepreneur with a reputation $\operatorname{cost} c_{j} \leq c^{\circ}$, will find it worthwhile to be corrupted and then the optimal equilibrium will be $\mathbf{C}$. In this equilibrium, the entrepreneur will obtain a consumption expected growth rate equal to:

$$
\gamma_{j}^{C}=\frac{1}{\sigma}\left[a_{M}-\frac{\left(a_{M}-a_{T}\right)(1-q)}{2}-\frac{q c_{j}}{2}-\rho\right] .
$$

- The entrepreneur with a reputation $\operatorname{cost} c_{j}>c^{\circ}$, will find it worthwhile to be honest and then, the optimal equilibrium will be NC. In this equilibrium, the entrepreneur will obtain a constant consumption growth rate equal to:

$$
\gamma^{N C}=\frac{1}{\sigma}\left[a_{M}-\rho\right]
$$

Furthermore, it can easily be demonstrated that capital and income also have the same expected growth rate ${ }^{21}$.

Then, at aggregate level, we obtain an income expected growth rate $\gamma$ weighting over different expected growth rates for corresponding entrepreneurs. Then, in the equilibrium $\mathbf{C}$, there will be $F\left(c^{\circ}\right)$ corrupted entrepreneurs, each with her/his own expected growth rate $\gamma_{j}^{C}$; in the equilibrium NC there will be $\left[1-F\left(c^{\circ}\right)\right]$ honest entrepreneurs, all with the same growth rate $\gamma^{N C}$. At the aggregate level, we have:

$$
\begin{gathered}
\gamma=\frac{1}{\sigma} \cdot\left[1-\left(1-\left(c^{\circ}\right)^{\alpha_{1}}\right)^{\alpha_{2}}\right] \cdot\left[a_{M}-\frac{\left(a_{M}-a_{T}\right)(1-q)}{2}-\rho\right]- \\
-\frac{1}{2 \sigma}\left[q \int_{0}^{c^{\circ}} c d c\right]+\frac{1}{\sigma} \cdot\left[1-\left(c^{\circ}\right)^{\alpha_{1}}\right]^{\alpha_{2}}\left(a_{M}-\rho\right)= \\
=\frac{\left(a_{M}-a_{T}\right)(1-q)}{2 \sigma} \cdot\left[1-\left(c^{\circ}\right)^{\alpha_{1}}\right]^{\alpha_{2}}-\frac{q}{4 \sigma} \cdot\left(c^{\circ}\right)^{2}+\frac{1}{\sigma} \cdot\left[a_{M}-\frac{\left(a_{M}-a_{T}\right)(1-q)}{2}-\rho\right] .
\end{gathered}
$$

By substituting $c^{\circ}=\frac{\left(a_{M}-a_{T}\right)(1-q)}{q}-2 m$ into (21), we obtain the economy expected growth rate as

$$
\begin{gathered}
\gamma=\frac{\left(a_{M}-a_{T}\right)(1-q)}{2 \sigma} \cdot\left[1-\left(\frac{\left(a_{M}-a_{T}\right)(1-q)}{q}-2 m\right)^{\alpha_{1}}\right]^{\alpha_{2}}- \\
-\frac{q}{4 \sigma} \cdot\left(\frac{\left(a_{M}-a_{T}\right)(1-q)}{q}-2 m\right)^{2}+\frac{1}{\sigma} \cdot\left[a_{M}-\frac{\left(a_{M}-a_{T}\right)(1-q)}{2}-\rho\right] .
\end{gathered}
$$

A straightforward computation gives that

$$
\frac{\partial \gamma}{\partial q}>0
$$

\footnotetext{
${ }^{21}$ See Appendix F for the proof.
} 
This means that the expected growth rate of the economy increases as the probability of being reported grows.

Remark 3.4. Relation in (23) holds, for each chosen probability distribution describing the cost function. Indeed, for a generic cumulative function $F$, we can write:

$$
\begin{gathered}
\gamma=\frac{1}{\sigma} \cdot\left\{1-F\left(\frac{\left(a_{M}-a_{T}\right)(1-q)}{q}-2 m\right) \cdot \frac{\left(a_{M}-a_{T}\right)(1-q)}{2}-\right. \\
\left.-\frac{q}{4 \sigma} \cdot\left[\left(\frac{\left(a_{M}-a_{T}\right)(1-q)}{q}-2 m\right)^{2}+a_{M}-\frac{\left(a_{M}-a_{T}\right)(1-q)}{2}-\rho\right]\right\},
\end{gathered}
$$

and also in this case $\gamma$ increases with respect to $q$, since $F$ increases by definition.

Despite the argument laid out in Remark 3.4, we prefer to show a very general but specific density function which applies to a multitude of cases, in order to avoid results that can be difficult to interpret. In this respect, the next section contains an explanation of how the relationship between the expected growth rate and the monitoring level works, by considering an endogenous optimal monitoring level.

\section{Endogenous monitoring}

As we have stated, $q$ is the probability of being reported and it derives from the probability $p$ of being monitored and from the probability $1-1 / n$ of the bureaucrat belonging to a different ethnic group from that of the controller (see formula (10)).

So far, we have taken the monitoring level $p$ as exogenous, but now we make the analysis more realistic, considering that the monitoring level set by the controller results from maximization of her/his payoff $V_{p}$ :

$$
V_{p}=\alpha p-\chi(n, p) .
$$

where $\alpha p$ are the benefits of a certain monitoring level $p$ for the controller and $\chi(n, p)$ are monitoring costs, dependent on $n$ and $p$.

The optimum level of $p$, named $p^{*}$, is derived by maximization of the controller's expected payoff function in (25).

The controller decides the optimal level of monitoring $p^{*}$ comparing the marginal benefit of a certain monitoring level with the cost of doing it. We state some assumptions about the cost function: costs are assumed to be null in the case of absence of monitoring, as it naturally should be. Moreover, we assume that the marginal costs increase as the monitoring level increases. In fact, comprehensive monitoring activity implies increased costs, 
since it requires a more sophisticated action and the specialist knowledge about complex corrupted transactions. As a further requirement, we hypothesize that the costs related to a fixed monitoring level grows as ethnic fractionalization $n$ increases. This assumption is driven by the growing complexity for any given group of interacting with a larger number of ethnic groups, also considering the evident presence of linguistic difficulties of monitoring members of different ethnic groups ${ }^{22}$. Wrong (2009), describing the "artificial" increase in ethnic groups which was forced onto Kenya by colonialism, makes a forceful supporting argument:

"by 1938, Kenya had been partitioned into twenty-four overcrowded native reserves "Kamba" for the Kamba people, "Kikuyu" for the Kikuyu, and so on and the fertile "White Highlands" for exclusive European use, where Africans could not own land. [...] The settlers wanted Africans to act small, think local. It made them so more manageable. [...] To those on the reserves, who increasingly viewed their communities as mini-nations in fierce competition with one another, Kenyans from outside were "foreigners". "Most of us on the farm rarely met people from other communities, spoke their language or participated in their cultural practices"[the future Nobel Peace Prize-winner Wanri Maathai remarked].".

The necessity of summing up the above statements and remarks drives the choice of an appropriate cost function. In this respect, we achieve our target by introducing the mathematical concept of Orlicz functions ${ }^{23}$. In doing so, we incur the cost of a rather complicated mathematical tool, but we also admit that it is worth incurring this cost. Indeed, the constitutive elements of the concept of Orlicz functions are so general and basic that Orlicz functions may be suitable for modeling purposes. In this respect, as we will see below, an Orlicz function describes well the main features of the monitoring costs. ${ }^{24}$

The costs $\chi$ are defined as:

$$
\chi(n, p)=g(n) M(p),
$$

where:

- $g: \mathbb{N} \rightarrow[0,+\infty)$ describes how the monitoring level cost depends on the number of ethnic groups. We point out that, in our analysis,

\footnotetext{
${ }^{22}$ See, e.g., Ortega and Tångeras (2008).

${ }^{23}$ For the concept of Orlicz functions and kernels see Appendix G, where some illustrative examples are also provided.

${ }^{24}$ It is worth noting that we are not the pioneers of the use of special functions like those of Orlicz type for economic modeling purposes, even if this technique is rather recent. In this respect, we refer to Boucekkine and Ruiz-Tamarit (2008) and Boucekkine et al. (2008) where it is shown that the solution to a two-sector Lucas-Uzawa model of endogenous growth can be expressed in terms of hypergeometric-type function. In Benchekroun and Withagen (2010), the exponential integrals are applied for modeling an economy with resource constraints.
} 
the trivial case of a single ethnic group is not considered, and the population is made up of at least two different ethnic groups. We can assume that we know the value of $g$ in the case of two different ethnic groups, with value $g(2)=g_{2}>0$. Function $g$ is also assumed to be increasing;

- $M$ has support in $[0,1], M([0,1]) \equiv[0, \bar{H}], \bar{H}>0$ and $M$ is a truncation of an Orlicz function as follows:

$$
M(x):=\nVdash_{\{x \in[0,1]\}} \cdot \Gamma(x),
$$

where $\nVdash_{A}$ is the usual characteristic function of the set $A$ and $\Gamma(x)$ is an Orlicz function such that $\Gamma(1) \equiv M(1)=\bar{H}$. We assume that the kernel function of $\Gamma$, named $h$, is strictly increasing.

The concept of Orlicz function is not new in the economic literature. In this respect, it is well-known that the properties of this mathematical tool are suitable to characterize a class of risk measures used in actuarial science (Haezendock and Goovaerts, 1982; Schmidt, 1989; Goovaerts et al., 2004; Bellini and Rosazza Gianin, 2008). As already stressed in the discussion developed above, we feel that the Orlicz functions can be also used to describe well the cost functions introduced in our model, with a particular focus on the relationship between monitoring level and fractionalization.

In our framework, the highest monitoring level is attained for $m=1$. In this case the cost function is:

$$
\chi(n, 1)=g(n) \bar{H},
$$

and it depends on the ethnic fractionalization within the country in that it depends on the term $g(n)$.

The function $V_{p}$ of the monitoring activity, for the controller, is maximized for an optimal monitoring level $p^{*}$, which can be found by imposing the first order condition:

$$
\frac{\partial V_{p}}{\partial p}=\alpha-g(n) h\left(p^{*}\right)=0 .
$$

Since $h$ is strictly increasing, then there exists the inverse function $h^{-1}$. We assume hereafter the following condition for the weights $g(n)$.

$$
g(n) \geq \frac{\alpha}{h(1)}, \quad \forall n \in \mathbb{N} .
$$

Condition (27) states that the cost adjustment factor $g(n)$ is not less than a certain threshold depending on the monitoring costs and the marginal benefit of monitoring.

By imposing (27), we can find the optimal monitoring level $p^{*} \in[0,1]$ given by:

$$
p^{*}=h^{-1}\left(\frac{\alpha}{g(n)}\right) \text {. }
$$


By considering the continuous version of the function $g:[0,+\infty) \rightarrow[0,+\infty)$, assuming that $g$ is differentiable and replacing the discrete variable $n$ with the continuous variable $x$, we can compute the first derivative of $p^{*}$,

$$
\left(p^{*}\right)^{\prime}(x)=\frac{1}{h^{\prime}(\alpha / g(x))} \cdot \frac{-\alpha g^{\prime}(x)}{g^{2}(x)}<0,
$$

since $g$ is increasing respect to $n$.

Thus, the assumption that $g$ is increasing implies that the optimal monitoring level decreases as the number of ethnic groups grows. This is due to the fact that the monitoring costs grow as the number of ethnic groups increases.

By substituting the optimal $p^{*}$ of (28) into (10), we find the optimal probability of being reported $q^{*}$ :

$$
q^{*}=h^{-1}\left(\frac{\alpha}{g(n)}\right) \cdot\left(1-\frac{1}{n}\right) .
$$

Then the optimal probability of being reported $q^{*}$ depends on ethnolinguistic fractionalization through two channels:

(1) the optimal monitoring level: as ethnic diversity increases, we have shown that the monitoring cost also increases and thus the optimal monitoring level $p^{*}$ declines;

(2) the probability of the bureaucrat belonging to a different ethnic group from that of the controller: as the number of ethnic groups increases, the probability of the bureaucrat belonging to the same ethnic group decreases. Therefore the probability of the bureaucrat belonging to a different ethnic group from that of the controller increases.

More intuitively, on the one hand, as ethnic diversity increases, the monitoring cost increases and then the optimal monitoring level decreases, thus the optimal $q^{*}$ decreases. On the other hand, as ethnic diversity increases, the probability of the bureaucrat belonging to a different ethnic group from that of the controller increases. Uniting these two opposite channels we will show (see Theorem 4.1.) that, subject to a non restrictive assumption regarding $g$, there is a threshold value of ethnic diversity $n^{*}$ where the probability of being reported reaches a maximum. For lower fractionalization levels, i.e. before $n^{*}$, the probability of being reported $q^{*}$ increases with respect to ethnic diversity $n$. Indeed, the increase in the probability of being reported -due to the fact that the bureaucrat belongs to a different ethnic group from that of the controller- overtakes the reduction in monitoring level -due to the increasing monitoring cost-. For high fractionalization levels, i.e. after $n^{*}$, the growing monitoring costs overtake the increase in the probability of being reported. 
These results are reflected in the aggregate expected growth rate. We define by $\gamma^{*}$ the expected growth rate computed at the optimal monitoring level $p^{*}$ (and so at the optimal level $q^{*}$ ) by substituting (30) and (28) into (21) as follows:

$$
\begin{gathered}
\gamma^{*}=\frac{\left(a_{M}-a_{T}\right)\left(1-q^{*}\right)}{2 \sigma} \cdot\left[1-\left(\frac{\left(a_{M}-a_{T}\right)\left(1-q^{*}\right)}{q^{*}}-2 m\right)^{\alpha_{1}}\right]^{\alpha_{2}}- \\
-\frac{q^{*}}{4 \sigma} \cdot\left(\frac{\left(a_{M}-a_{T}\right)\left(1-q^{*}\right)}{q^{*}}-2 m\right)^{2}+\frac{1}{\sigma} \cdot\left[a_{M}-\frac{\left(a_{M}-a_{T}\right)\left(1-q^{*}\right)}{2}-\rho\right] .
\end{gathered}
$$

We measure the corruption level with the fraction of corrupted entrepreneurs, given by (14). By substituting (30) into (14), we have:

$$
F\left(c^{\circ}\right)^{*}=1-\left(1-\left(\frac{\left(a_{M}-a_{T}\right)\left(1-q^{*}\right)}{q^{*}}-2 m\right)^{\alpha_{1}}\right)^{\alpha_{2}} .
$$

This formula shows that, before $n^{*}$, as ethnic diversity increases, corruption -via the increasing probability of being reported $q^{*}$ - decreases; conversely, after $n^{*}$ as ethnic diversity increases, corruption also increases, due to the decreasing probability of being reported $q^{*}$.

In the next result, the previous arguments are formalized:

Theorem 4.1. Consider a function $g$ such that

$$
g\left(n^{*}\right)=\frac{\alpha}{h\left(\frac{K n^{*}}{n^{*}-1}\right)},
$$

for $n^{*} \in \mathbb{N}$, with

$$
K=h^{-1}\left(\alpha / g_{2}\right)
$$

Moreover, suppose that

$$
\left\{\begin{array}{l}
h^{\prime \prime}\left(\frac{\alpha}{g\left(n^{*}\right)}\right)<0 ; \\
\frac{g^{\prime \prime}\left(n^{*}\right)}{g^{\prime}\left(n^{*}\right)}>\frac{2 g^{\prime}\left(n^{*}\right)}{g\left(n^{*}\right)} .
\end{array}\right.
$$

Then $n^{*}$ is the unique absolute maximum point for $q^{*}$ and for $\gamma^{*}$, and it is the unique absolute minimum point for $\left(c^{\circ}\right)$.

For the proof see Appendix H.

Remark 4.2. The hypotheses contained in (35) are rather general: the first one is implied by the concavity of $h$, while the second one can be interpreted as a condition on the risk-aversion, whenever $g$ is assumed to be an utility function. In this respect, it is worth recalling that the ratio $-g^{\prime \prime} / g^{\prime}$ is the Arrow-Pratt risk-aversion coefficient of the utility function $g$. 
In Theorem 4.1, we showed that ethnolinguistic diversity increases the monitoring activity level, up to a critical ethnolinguistic threshold $n^{*}$. In this case, the expected growth rate increases and the corruption level declines. For high fractionalization levels, i.e. after $n^{*}$, the growing monitoring costs reduce the monitoring level and thus economic growth.

Moreover, the dynamic analysis shows an inverted U-curve between ethnolinguistic fractionalization and the expected growth rate. Indeed, we showed that, in the case of very fragmented countries or, conversely, in a homogeneous society, the economy has a low expected growth rate and widespread corruption, while in intermediate fragmented countries, the economy has a high expected growth rate and limited corruption.

\section{Conclusion}

In this work, we have analyzed the influence of cultural and ethnic factors on the spread of corruption. The theoretical and empirical literature has stressed how greater ethnolinguistic fractionalization can produce greater corruption; in our model, as a further result, we have shown that intermediate ethnolinguistic fractionalization makes the control system more incisive on the bureaucrat's behavior, and thus might reduce corruption.

A theoretical game model is presented, in order to explore the relationship between ethnolinguistic fractionalization, corruption and the growth rate. Very general conditions on the model's parameters are assumed. In particular, we state that the reputation costs follow a Kumaraswamy distribution, which belongs to the family of two-parameter distribution but, differently from the Beta law, it is explicitly tractable from a mathematical point of view.

We find an ethnolinguistic threshold $n^{*}$ such that before $n^{*}$ the expected growth rate grows and the corruption level declines. For higher fractionalization levels, i.e. after $n^{*}$, the growing monitoring costs drive growing corruption and a low economic growth and monitoring level.

The dynamic analysis shows a U-curve between ethnolinguistic fractionalization and the expected growth rate: in the case of a highly fractionalized society or, conversely, in a homogeneous society, the economy has a low expected growth rate, while in the middle of the range of ethnic diversity, the economy has a high expected growth rate and limited corruption. 


\section{A Appendix}

World Countries are:

Afghanistan; Albania; Algeria; Angola; Antigua and Barbuda; Argentina; Armenia; Australia; Austria; Azerbaijan; Bahamas; Bangladesh; Barbados; Belarus; Belgium; Belize; Benin; Bermuda; Bhutan; Bolivia; Bosnia and Herzegovina; Botswana; Brazil; Brunei; Bulgaria; Burkina Faso; Burundi; Cambodia; Cameroon; Canada; Cape Verde; Central African Republic; Chad; Chile; China; Colombia; Comoros; Congo, Dem. Rep.; Congo, Republic of; Costa Rica; Cote d'Ivoire; Croatia; Cuba; Cyprus; Czech Republic; Denmark; Djibouti; Dominica; Dominican Republic; Ecuador; Egypt; El Salvador; Equatorial Guinea; Eritrea; Estonia; Ethiopia; Fiji; Finland; France; Gabon; Gambia, The Georgia; Germany; Ghana; Greece; Grenada; Guatemala; Guinea; Guinea-Bissau; Guyana; Haiti; Honduras; Hong Kong; Hungary; Iceland; India; Indonesia; Iran; Iraq; Ireland; Israel; Italy; Jamaica; Japan; Jordan; Kazakhstan; Kenya; Kiribati; Korea, Republic of; Kuwait; Kyrgyzstan; Laos; Latria; Lebanon; Lesotho; Liberia; Libya; Lithuania; Luxembourg; Macao; Macedonia; Madagascar; Malawi; Malaysia; Mali; Malta; Marshall Islands; Mauritania; Mauritius; Mexico; Micronesia, Fed. Sts.; Moldova; Mongolia; Morocco; Mozambique; Namibia; Nepal; Netherlands; New Zealand; Nicaragua; Niger; Nigeria; Norway; Oman; Pakistan; Panama; Papua New Guinea; Paraguay; Peru; Philippines; Poland; Portugal; Qatar; Romania; Russia; Rwanda; Sao Tome and Principe; Saudi Arabia; Senegal; Seychelles; Sierra Leone; Singapore; Slovak Republic; Slovenia; Solomon Islands; Somalia; South Africa; Spain; Sri Lanka; St. Kitts \& Nevis; Sudan; Suriname; Swaziland; Sweden; Switzerland; Syria; Taiwan; Tajikistan; Tanzania; Thailand; Togo; Tonga; Trinidad; Tobago; Tunisia; Turkey; Turkmenistan; Uganda; Ukraine; United Arab Emirates; United Kingdom; United States; Uruguay; Uzbekistan; Vanuatu; Venezuela; Vietnam; Zambia; Zimbabwe.

Democratic countries, considering the indications of Freedom House (http://www.democracyweb.org/new-map/), are:

Antigua and Barbuda; Argentina; Australia; Austria; Bahamas; Barbados; Belgium; Belize; Benin; Botswana; Brazil; Bulgaria; Canada; Cape Verde; Chile; Costa Rica; Croatia; Cyprus; Czech Republic; Denmark; Domenica; Dominican Republic; El Salvador; Estonia; Finland; France; Germany; Ghana; Greece; Grenada; Hungary; Iceland; India; Indonesia; Ireland; Israel; Italy; Jamaica; Japan; Kiribati; Latria; Lithuania; Luxembourg; Mali; Malta; Marshall Islands; Mauritius; Mexico; Micronesia, Fed. Sts.; Mongolia; Namibia; Netherlands, New Zealand; Norway; Panama; Peru; Poland; Portugal; Romania; Slovak Republic; Slovenia; South Africa; Spain; Suriname; Sweden; Switzerland; Taiwan; Trinidad \& Tobago; Ukraine; United Kingdom; United States; Uruguay; Vanuatu.

OECD Countries are: 
Australia, Austria, Belgium, Canada, Czech Republic; Denmark, Finland; France; Germany; Greece; Hungary; Iceland; Ireland; Italy; Japan; Korea; Luxembourg; Mexico; Netherlands; New Zealand; Norway; Poland; Portugal; Slovak Republic; Spain; Sweden; Switzerland; Turkey; United Kingdom; United States.

\section{B Appendix}

Let $\underline{\pi}_{\Delta}=\underline{\pi}_{4}-\underline{\pi}_{3}=\left(\pi_{\Delta}^{(E)}, \pi_{\Delta}^{(B)}\right)$ be the vector of the differences in the expected payoffs where $\underline{\pi}_{4}$ is the agreement about the bribe and where $\underline{\pi}_{3}$ is disagreement between bureaucrat and entrepreneur. The bribe $b^{N B}$ associated to the Nash solution to a bargaining game is the solution of the following maximum problem

$$
\max _{b \in(0,+\infty)}\left(\pi_{\Delta}^{(E)} \cdot \pi_{\Delta}^{(B)}\right)
$$

i.e.

$\max _{b \in(0,+\infty)}\left\{\left[a_{M} k-(1-q) b-q c_{j} k-q a_{M} k-a_{T} k(1-q)\right] \cdot[w-m k q+(1-q) b-w+m k q]\right\}$,

that is the maximum of the product between the elements of $\underline{\pi}_{\Delta}$ and where $\left[q a_{M} k+(1-q) a_{T} k, w-m k q\right]$ is the point of disagreement, i.e. the expected payoffs that the entrepreneur and the bureaucrat respectively would obtain if they did not come to an agreement. Since the objective function is concave with respect to $b$, a sufficient condition for $b$ being a maximum is the first order condition

$$
\frac{\partial\left(\pi_{\Delta}^{(E)} \cdot \pi_{\Delta}^{(B)}\right)}{\partial b}=0
$$

that leads in this case to:

$$
\begin{gathered}
\left(a_{M}-a_{T}\right) k(1-q)^{2}-c_{j} q(1-q) k-2 b(1-q)^{2}=0 \Leftrightarrow \\
\Leftrightarrow 2 b(1-q)^{2}=\left(a_{M}-a_{T}\right) k(1-q)^{2}-c_{j} q(1-q) k,
\end{gathered}
$$

bringing to:

$$
b^{N B}=\left[\frac{\left(a_{M}-a_{T}\right) k}{2}-\frac{c_{j} k q}{2(1-q)}\right]
$$

that is the unique equilibrium bribe in the last subgame, $\forall q \neq 1$.

\section{Appendix}

The static game is solved with the backward induction method. Starting from stage 3, the entrepreneur needs to decide whether to negotiate with the bureaucrat. Both expected payoffs are then compared, because the bureaucrat asked for a bribe. 
(3) At stage three the entrepreneur negotiates the bribe if and only if

$$
\pi_{4}^{(E)}>\pi_{3}^{(E)} \Leftrightarrow a_{M} k-(1-q) b^{N B}-c_{j} k q>q a_{M} k+(1-q) a_{T} k
$$

i.e. the entrepreneur expected payoff negotiated is greater than her/his expected payoff in the case of refusal. Since under a perfect information hypothesis, the entrepreneur knows the final equilibrium bribe $b^{N B}$ then we substitute this value in the previous inequality and, by simplification, we obtain

$$
a_{M} k-\frac{\left(a_{M}-a_{T}\right)(1-q) k}{2}-\frac{c_{j} k q}{2}>q a_{M} k+(1-q) a_{T} k,
$$

that is equivalent to:

$$
\frac{\left(a_{M}-a_{T}\right)(1-q) k}{2}-\frac{c_{j} k q}{2}>0
$$

that is verified $\forall c_{j}<\frac{\left(a_{M}-a_{T}\right)(1-q)}{q}=c^{\star}$.

Notice that in order to have an admissible probability set, $c_{j}$ must belong to $[0,1]$. Since $a_{M}>a_{T}$, then we have

$$
c^{\star}=\frac{\left(a_{M}-a_{T}\right)(1-q)}{q} \geq 0 .
$$

Generally, if $c_{j}<c^{\star}$ the entrepreneur negotiates the bribe, while if $c_{j} \geq c^{\star} \mathrm{s} /$ he refuses the bribe.

(2) Going up the decision-making tree, at stage two, the bureaucrat decides whether to ask for a bribe.

- If $c_{j} \geq c^{\star}$ then the bureaucrat knows that the entrepreneur will not accept any bribe. Therefore, $\mathrm{s} /$ he will be honest and $\mathrm{s} /$ he will pursue the concession without any bribe: indeed the bureaucrat expected payoff if not asking for a bribe $w$ is greater than her/his expected payoff if $\mathrm{s} /$ he asks for a bribe $w-m k q$.

- If $c_{j}<c^{\star}$ then the bureaucrat knows that if $\mathrm{s} /$ he asks for a bribe then the entrepreneur will enter into negotiation and the final bribe will be $b^{N B}$. Then at stage two the bureaucrat asks for a bribe if and only if

$$
\pi_{4}^{(B)}>\pi_{2}^{(B)} \quad \Leftrightarrow \quad w-m k q+(1-q) b^{N B}>w
$$

i.e. the bureaucrat expected payoff if asking for a bribe is greater than her/his expected payoff if $\mathrm{s} /$ he does not ask for a bribe. By substituting $b^{N B}$ in the previous inequality and after some algebra, we obtain

$$
c_{j}<c^{\circ}=\frac{\left(a_{M}-a_{T}\right)(1-q)}{q}-2 m .
$$


Because $c^{\circ}<c^{\star}$, so we can conclude that if $c_{j}<c^{\circ}$ then the bureaucrat asks for the bribe $b^{N B}$ and the entrepreneur accepts. If, $c_{j} \geq c^{\circ}$, the bureaucrat will not find it worthwhile to ask for a bribe.

(1) At stage one the entrepreneur has to decide whether to submit the project.

- If $c_{j} \geq c^{\circ}$ then the entrepreneur knows that if $\mathrm{s} /$ he submits a project no bribe will be asked for. So $\mathrm{s} /$ he will submit the project if and only if

$$
\pi_{2}^{(E)}>\pi_{1}^{(E)} \quad \Leftrightarrow \quad a_{M}<a_{T}
$$

The previous inequality is always verified by hypothesis.

- If $c_{j}<c^{\circ}$ then the entrepreneur knows that the bureaucrat will ask for the bribe $b^{N B}$ which $\mathrm{s} /$ he will accept. So, at stage one, s/he has to decide whether to invest in the modern technology. S/he will invest in the modern technology if and only if

$$
\pi_{1}^{(E)}<\pi_{4}^{(E)} \Leftrightarrow a_{M} k-\frac{\left(a_{M}-a_{T}\right)(1-q) k}{2}-\frac{k q c_{j}}{2}>a_{T} k,
$$

hence:

$$
c_{j}<c^{\star \star}=\frac{\left(a_{M}-a_{T}\right)(1+q)}{q} .
$$

Because $c^{\star \star}>c^{\star}>c^{\circ}$, so we can conclude that if $c_{j}<c^{\circ}$ the entrepreneur invests in the modern technology with corruption, while if $c_{j} \geq c^{\circ}$ the entrepreneur invests in the modern technology without corruption.

\section{Appendix}

The Kumaraswamy law belongs to the family of the two-parameters distributions, being the Beta distribution the most famous. A very important feature of the Kumaraswamy random variable is its mathematical tractability, since an explicit form of its distribution function is available. Indeed, given $\alpha_{1}, \alpha_{2} \in(0,+\infty)$, the density function $f$ and the distribution function $F$ of a Kumaraswamy random variable are, respectively:

$$
\begin{gathered}
f(c)=\alpha_{1} \alpha_{2} c^{\alpha_{1}-1}\left(1-c^{\alpha_{1}}\right)^{\alpha_{2}-1}, \quad c \in[0,1] ; \\
F(c)=1-\left(1-c^{\alpha_{1}}\right)^{\alpha_{2}}, \quad c \in[0,1] .
\end{gathered}
$$

To be more exhaustive, the graphs of the Kumaraswamy density and distribution functions related to some choices of $\alpha_{1}$ and $\alpha_{2}$ are shown in Figures 2 and 3 . As the Figures show, the shape of the Kumaraswamy density function changes as the values of $\alpha_{1}$ and $\alpha_{2}$ vary. Therefore, this probability law is suitable for describing different types of ethical behaviors 

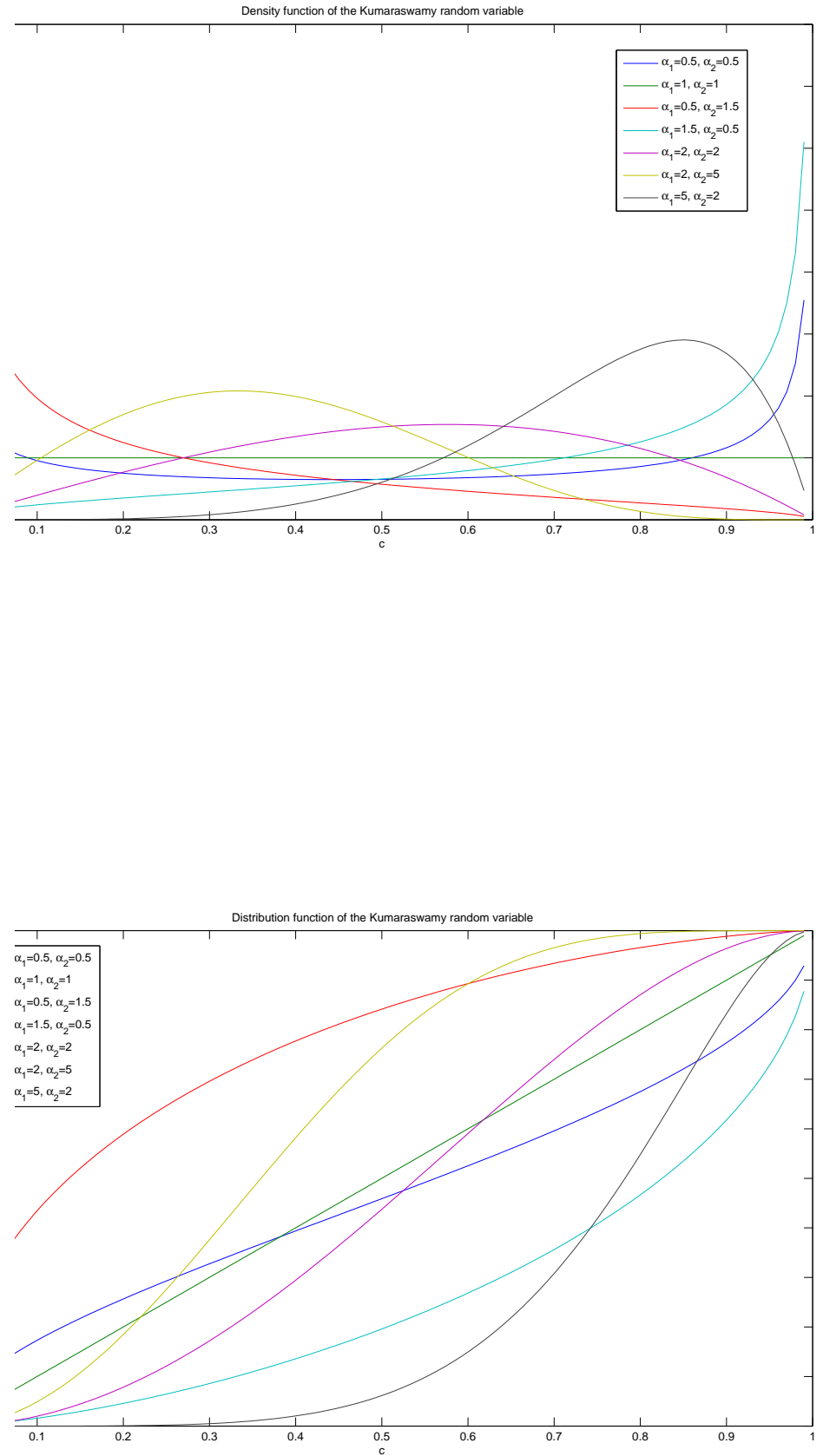
of entrepreneurs.

More specifically, if $1<\alpha_{2}<\alpha_{1}$, then the shape of the distribution function is asymmetric to the right, describing entrepreneurs with high reputation costs. Conversely, when $1<\alpha_{1}<\alpha_{2}$, then we have asymmetry to the left, and the entrepreneurs have low reputation costs. If $\alpha_{1}=\alpha_{2}=1$, then the Kumaraswamy distribution reduces to the uniform distribution ${ }^{25}$.

\section{E Appendix}

In the equilibrium with corruption (equilibrium $\mathbf{C}$ ), the expected entrepreneur's profit is:

$$
\Pi_{E}^{C}=k\left[a_{M}-\frac{\left(a_{M}-a_{T}\right)(1-q)}{2}-\frac{c_{j} q}{2}\right],
$$

thus the constraint is:

$$
\dot{k}=k\left[a_{M}-\frac{\left(a_{M}-a_{T}\right)(1-q)}{2}-\frac{c_{j} q}{2}\right]-C .
$$

The Hamiltonian function $H(C, k, \lambda)$ is:

$$
H=e^{-\rho t} \frac{C^{1-\sigma}-1}{1-\sigma}+\lambda\left[k\left(a_{M}-\frac{\left(a_{M}-a_{T}\right)(1-q)}{2}-\frac{c_{j} q}{2}\right)-C\right],
$$

where $\lambda$ is a costate variable. Optimization provides the following first-order conditions:

$$
\frac{\partial H(C, k, \lambda)}{\partial C}=e^{-\rho t} C^{-\sigma}-\lambda=0,
$$

and

$$
-\frac{\partial H(C, k, \lambda)}{\partial \lambda}=\dot{\lambda} \Longleftrightarrow-\lambda\left[a_{M}-\frac{\left(a_{M}-a_{T}\right)(1-q)}{2}-\frac{c_{j} q}{2}\right]=\dot{\lambda} .
$$

By deriving the first condition, the expected consumption growth rate is obtained:

$$
\gamma_{j}^{C}=\frac{1}{\sigma}\left[a_{M}-\frac{\left(a_{M}-a_{T}\right)(1-q)}{2}-\frac{c_{j} q}{2}-\rho\right] .
$$

In equilibrium $\mathbf{N C}$, the entrepreneur's profit is:

$$
\Pi_{E}^{N C}=a_{M} k,
$$

thus the constraint is:

$$
\dot{k}=a_{M} k-C .
$$

\footnotetext{
${ }^{25}$ We stress that the distinction provided above on the reputation costs of the entrepreneurs has to be viewed as a particular feature of the Kuramaswamy distribution, that explains the relevance of this random variable for modeling purposes. As we have shown in Remark 3.4, the analysis disregards the particular shape of function $F$.
} 
The Hamiltonian function $H(C, k, \lambda)$ is:

$$
H=e^{-\rho t} \frac{C^{1-\sigma}-1}{1-\sigma}+\lambda\left[a_{M} k-C\right] .
$$

A straightforward computation gives the following expression for the constant consumption growth rate:

$$
\gamma^{N C}=\frac{1}{\sigma}\left[a_{M}-\rho\right]
$$

\section{F Appendix}

At a steady state, everything grows at the same rate and therefore $\frac{\dot{k}}{k}$ is constant. At equilibrium $\mathbf{C}$ we know that

$$
\frac{\dot{k}}{k}=a_{M}-\frac{\left(a_{M}-a_{T}\right)(1-q)}{2}-\frac{c_{j} q}{2}-\frac{C}{k} .
$$

Since $\frac{\dot{k}}{k}$ is constant, then the difference between both terms on the right should also be constant, and because $a_{M}, a_{T}, c$ and $q$ are constant, then $C$ and $k$ should grow at the same rate. Similarly, since $y=a_{M} k$, at a steady state income grows at the same rate as capital. The same applies in the case of equilibrium NC.

\section{G Appendix}

$M:[0,+\infty) \rightarrow[0,+\infty)$ is an Orlicz function if and only if it is continuous, convex and nondecreasing in $[0,+\infty), M(0)=0, M(x)>0$ for $x>0$ and $\lim _{x \rightarrow+\infty} M(x)=+\infty$. Krasnoselskii and Rutitsky (1961) proved a representation theorem, stating that given an Orlicz function $M$, there exists a function $h:[0,+\infty) \rightarrow[0,+\infty)$ such that

$$
M(x)=\int_{0}^{x} h(t) d t
$$

where $h(t)$ is right-differentiable for $t \geq 0, h(0)=0, h(t)>0$ for $t>0, h$ is nondecreasing and $\lim _{t \rightarrow+\infty} h(t)=+\infty$. $h$ is known as the kernel of the Orlicz function $M$. In our model, the analysis is restricted to the case of $h$ strictly increasing.

We now list some noticeable examples of Orlicz functions $M$ together with the related kernel $h$. The derivation of the kernel is obtained by applying 
formula (53).

$$
\begin{cases}M(x)=x^{2}, & \text { with } h(x)=2 x \\ M(x)=a x^{k} & \text { with } h(x)=a k x^{k-1}, a>0 \text { and } k>1 \\ M(x)=x^{2} e^{x} & \text { with } h(x)=x(x+2) e^{x} \\ M(x)=x^{\alpha} e^{\beta x} & \text { with } h(x)=\left(\alpha x^{\alpha-1}+\beta x^{\alpha}\right) e^{\beta x}, \alpha>1 \text { and } \beta>0\end{cases}
$$

As examples in (54) show, the set of Orlicz function is rather wide, and contains some types of polynomials as well as exponentials.

\section{H Appendix}

Define the function $q^{*}:[2,+\infty) \rightarrow \mathbb{R}$ such that

$$
q^{*}(x)=h^{-1}\left(\frac{\alpha}{g(x)}\right) \cdot\left(1-\frac{1}{x}\right) .
$$

The first order condition is

$$
\left(q^{*}\right)^{\prime}(x)=\frac{1}{h^{\prime}(\alpha / g(x))} \cdot \frac{-\alpha g^{\prime}(x)}{g^{2}(x)} \cdot\left(1-\frac{1}{x}\right)+h^{-1}\left(\frac{\alpha}{g(x)}\right) \cdot \frac{1}{x^{2}}=0 .
$$

Then

$$
\frac{1}{h^{\prime}(\alpha / g(x))} \cdot \frac{1}{h^{-1}(\alpha / g(x))} \cdot \frac{-\alpha g^{\prime}(x)}{g^{2}(x)}=\frac{1}{x(1-x)} .
$$

By integrating, we obtain

$$
\log \left(h^{-1}(\alpha / g(x))\right)-\log \left(h^{-1}(\alpha / g(2))\right)=\log \left(\frac{x}{x-1}\right), \quad x \geq 2 .
$$

A straightforward computation allows us to rewrite (56) as follows:

$$
h^{-1}(\alpha / g(x))=\frac{K x}{x-1},
$$

where $K=h^{-1}(\alpha / g(2))$. By (57) we have that:

$$
\exists\left(q^{*}\right)^{\prime}\left(x^{*}\right)=0 \Longleftrightarrow g\left(x^{*}\right)=\frac{\alpha}{h\left(\frac{K x^{*}}{x^{*}-1}\right)} .
$$

The second order conditions can be written as follows:

$$
\begin{gathered}
\left(q^{*}\right)^{\prime \prime}(x)=\frac{2}{x^{2}} \cdot \frac{\mathrm{d}}{\mathrm{d} x}\left(h^{-1}\left(\frac{\alpha}{g(x)}\right)\right)- \\
-\frac{2}{x^{3}} h^{-1}\left(\frac{\alpha}{g(x)}\right)+\frac{x-1}{x} \cdot \frac{\mathrm{d}^{2}}{\mathrm{~d} x^{2}}\left(h^{-1}\left(\frac{\alpha}{g(x)}\right)\right) .
\end{gathered}
$$


By (58), we get that a sufficient condition for $\left(q^{*}\right)^{\prime \prime}(x)<0$ is that

$$
\frac{\mathrm{d}^{2}}{\mathrm{~d} x^{2}}\left(h^{-1}\left(\frac{\alpha}{g(x)}\right)\right)<0 .
$$

By conditions in (35) and after some algebra, we obtain that condition (59) holds.

Returning to the discrete variable $n$ and imposing the boundary condition $g(2)=g_{2}$, we have that $g\left(n^{*}\right)$ can be written as in (33), with $K$ given by (34) and

$$
n^{*} \in\left\{\left[x^{*}\right],\left[x^{*}\right]+1\right\} \mid q\left(n^{*}\right)=\max \left\{q\left(\left[x^{*}\right]\right), q\left(\left[x^{*}\right]+1\right)\right\} .
$$

$n^{*}$ is the unique absolute maximum point for $q^{*}$.

The optimal expected growth rate $\gamma^{*}$ can be written as $\gamma^{*}(n):=\gamma\left(q^{*}(n)\right)$. Directly by formula (31), we observe that a straightforward computation gives that $\gamma^{*}$ has the same behavior as $q^{*}$, i.e. it has a unique maximum point in $n^{*}$ as well.

The costs at the optimal monitoring level $m^{*}$ are:

$$
\left(c^{\circ}\right)^{*}(n)=\frac{\left(a_{M}-a_{T}\right)\left(1-q^{*}(n)\right)}{q^{*}(n)}-2 m .
$$

Therefore

$$
\left(\left(c^{\circ}\right)^{*}\right)^{\prime}(n)=-\frac{\left(a_{M}-a_{T}\right)}{\left(q^{*}\right)^{2}(n)} \cdot\left(q^{*}\right)^{\prime}(n) .
$$

The coefficient of $\left(q^{*}\right)^{\prime}(n)$ in (60) is negative, and so $n^{*}$ is the unique minimum point for $\left(c^{\circ}\right)^{*}$. 


\section{References}

[1] Acemoglu D, Verdier T (1998) Property rights, Corruption and the Allocation of Talent: A General Equilibrium Approach. The Economic Journal 108: 1381-1403.

[2] Acemoglu D, Verdier T (2000) The Choice Between Market Failures and Corruption. American Economic Review 90(1): 194-211.

[3] Alesina A, Baqir R, Easterly W (1999) Public Goods and Ethnic Divisions. Quarterly Journal of Economics 114(4): 1243-1284.

[4] Alesina A, Devlseschawuer A, Easterly W, Kurlat S, Wacziarg R (2003) Fractionalization. Journal of Economic Growth 8(2): 155-94.

[5] Alesina A, Drazen A (1991) Why are Stabilizations Delayed? American Economic Review 81(5): 1170-1188.

[6] Alesina A, La Ferrara E (2005) Ethnic Diversity and Economic Performance. Journal of Economic Literature 43: 762-800.

[7] Alesina A, Spolaore E (1997) On the Number and Size of Nations. The Quarterly Journal of Economics 112(4): 1027-56.

[8] Allport G W (1954) The Nature of Prejudice. Beacon Press, Boston.

[9] Atlas Narodov Mira (1964) Moscow: Glavnoe upravlenie geodezii i cartografii.

[10] Bellini F, Rosazza Gianin E (2008) On Haezendonck risk measures. Journal of Banking and Finance 32(6): 986-994.

[11] Benchekroun H, Withagen C (2010) The Optimal Depletion of Exhaustible Resources: A Complete Characterization. Cahiers de recherche 04-2010, Centre interuniversitaire de recherche en conomie quantitative, CIREQ.

[12] Bhattacharyya S, Hodler R (2010) Natural Resources, Democracy and Corruption. European Economic Review 54(4): 608-21.

[13] Blackburn K, Bose N, Haque M Emranul (2010) Endogenous Corruption in Economic Development. Journal of Economic Studies 37(1): 4-25.

[14] Boucekkine R, Ruiz-Tamarit J (2008) Special functions of the study of economics dynamics: The case of the Lucas-Uzawa model. Journal of Mathematical Economics 44: 33-54. 
[15] Boucekkine R, Martinez B, Ruiz-Tamarit J (2008) Global dynamics and imbalance effects in the Lucas-Uzawa model. International Journal of Economic Theory 4(4): 503-518.

[16] Collier P (2001) Implications of Ethnic Diversity. Economic Policy 32(16): 127-66.

[17] Corneo G (2010) Nationalism, cognitive ability, and interpersonal relations. International Review of Economics 57: 19-41.

[18] Dobson S, Ramlogan-Dobson C (2010) Is There a Trade-Off between Income Inequality and Corruption? Evidence from Latin America. Economics Letters 107(2): 102-04.

[19] Drugov M (2010) Competition in Bureaucracy and Corruption. Journal of Development Economics 92(2): 107-14.

[20] Easterly W, Levine R (1997) Africa's Growth Tragedy: Policies and Ethnic Divisions. Quarterly Journal of Economics 112(4): 1203-1250.

[21] Evrensel A Y (2010) Corruption, Growth, and Growth Volatility. International Review of Economics and Finance 19(3): 501-14.

[22] Fisman R, Gatti R (2002) Decentralization and Corruption: Evidence across Countries. Journal of Public Economics 83(3): 325-45.

[23] Goovaerts M J, Kaas R, Dhaene J, Tang Q (2004) Some new classes of consistent risk measures. Insurance: Mathematics and Economics 34(3): 505-516.

[24] Haezendonck J, Goovaerts M (1982) A new premium calculation principle based on Orlicz norms. Insurance: Mathematics and Economics 1(1): 41-53.

[25] Krasnoselskii M A, Rutitsky Y B (1961) Convex Function and Orlicz Spaces. Groeningen, Netherlands.

[26] Lambsdorff J G (1998) An Empirical Investigation of Bribery in International Trade. European Journal of Development Research 10: $40-59$.

[27] La Porta R, Lopes de Silanes F, Shleifer A, Vishny R (1999) The Quality of Government. Journal of Law, Economics and Organization 15(1): $222-79$.

[28] Lessmann C, Markwardt G (2010) One Size Fits All? Decentralization, Corruption, and the Monitoring of Bureaucrats. World Development 38(4): 631-46. 
[29] Li H, Xu C L, Zou H (2000) Corruption, Income Distribution and Growth. Economics and Politics 12(2): 155-182.

[30] Mauro P (1995) Corruption and Growth. Quarterly Journal of Economics 110: 681-712.

[31] Mauro P (1997) The Effects of Corruption on Growth, Investment, and overnment Expenditure: a Cross-Country Analysis. In: Elliot K A Editor, Corruption in the Global Economy (Washington: Institute for International Economics).

[32] Musila J W, Siguè S P (2010) Corruption and International Trade: An Empirical Investigation of African Countries. World Economy 33(1): 129-146.

[33] Ortega J, Tångeras T P (2008) Unilingual Versus Bilingual Education: A Political Economy Analysis. Journal of the European Economic Association 6(5): 1078-1108.

[34] Rose-Ackerman S (1999) Corruption and Government. Cambridge University Press.

[35] Shleifer A, Vishny R (1993) Corruption. The Quarterly Journal of Economics 108(3): 599-617.

[36] Schmidt K D (1989) Positive Homogeneity and Multiplicativity of Premium Principles on Positive Risks. Insurance: Mathematics and Economics 8(4): 315-319.

[37] Svensson J (2000) Foreign Aid and Rent-seeking. Journal of International Economics 51: 437-461.

[38] Tajfel H, Billig M, Bundy R P, Flament C (1971) Social Categorization and Intergroup Behavior. European Journal of Social Psychology 1: 149-178.

[39] Tajfel H, Turner J C (1986) The Social Identity Theory of Inter-group Behavior. In: Worchel S, Austin L W (eds.), Psychology of Intergroup Relations. Chigago: Nelson-Hall.

[40] Tångeras T P, Lagerlöf N P (2009) Ethnic Diversity, Civil War and Redistribution. Scandinavian Journal of Economics 111(1): 1-27.

[41] Treisman D (2000) The Causes of Corruption: A Cross-National Study. Journal of Public Economics 76(3): 399-457.

[42] Vicente P C (2010) Does Oil Corrupt? Evidence from a Natural Experiment in West Africa. Journal of Development Economics 92(1): 28-38. 
[43] Wrong M (2009) It's Our Turn to Eat: The Story of a Kenyan WhistleBlower. New York: Harper.

[44] Yoo S H (2008) Petty Corruption. Economic Theory 37: 267-280. 